7. Reprod. Fert. (1975) 43, 405-410

\title{
THE PASSAGE OF SPERMATOZOA THROUGH THE CERVIX OF OVARIECTOMIZED EWES TREATED WITH PROGESTERONE AND OESTROGEN
}

\author{
K. P. GROKER,* T. J. ROBINSON AND J. N. SHELTON† \\ Department of Animal Husbandry, University of Sydney, \\ New South Wales, Australia 2006
}

(Received 4th Fune 1974)

\begin{abstract}
Summary. Thirty spayed ewes were used in a $2 \times 3$ split-plot factorial experiment $(\mathrm{n}=5)$ in which oestrus was induced with 30 or $90 \mu \mathrm{g}$ oestradiol benzoate (OB) following a period of progesterone priming. They were inseminated $36 \mathrm{hr}$ after oestrogen and the numbers of spermatozoa in the caudal, mid- and cranial regions of the cervix (sub-plots) were estimated 1, 12 and $24 \mathrm{hr}$ later. At each interval of time and for each region of the cervix, fewer spermatozoa were recovered from the ewes treated with $30 \mu \mathrm{g}$ OB than from those treated with $90 \mu \mathrm{g}(P<0.05)$.
\end{abstract}

\section{INTRODUCTION}

Allison \& Robinson (1972) demonstrated the importance of the balance of ovarian steroids in the initiation and maintenance of a cervical population of sr.m.matozoa following artificial insemination of ovariectomized ewes in which

rus was induced by oestrogen after priming with progesterone. They sug$\therefore d$ that an imbalance of progesterone and oestrogen could affect the trans-

t of spermatozoa by altering either the quantitative and qualitative characistics of the cervical secretions or the motility of the tract.

This paper reports an extension of that work.

\section{MATERIALS AND METHODS}

\section{Experimental design}

A split-plot factorial design was used, with the following form.

Main plots: dose of $\mathrm{OB}$ for induction of oestrus -30 or $90 \mu \mathrm{g}$; time of recovery of spermatozoa-1, 12 or $24 \mathrm{hr}$ after insemination; factorial $2 \times 3$; $\mathrm{n}=5 ; \mathrm{N}=30$.

Sub-plots: region of the cervix from which spermatozoa were recoveredcaudal, mid- or cranial; $30 \times 3=90$ observations.

Several months after ovariectomy, thirty mature medium-wool Merino ewes

* Present address: Sheep and Wool Branch, Department of Agriculture, South Perth, Western Australia 6151.

$\dagger$ Present address: Cobbitty Road, Cobbitty, New South Wales, Australia 2570. 
were injected intramuscularly daily for 12 days, each with $10 \mathrm{mg}$ progesterone in oil (Robinson, 1959), commencing 16 days before the date for insemination. A single injection of either $30 \mu \mathrm{g}$ or $90 \mu \mathrm{g}$ oestradiol benzoate (OB) was given $60 \mathrm{hr}$ after the final injection of progesterone. This was not necessarily the optimum dose for preparation of the tract for sperm transport (Allison \& Robinson, 1972), but it was selected because of the well established time/dose relationships between times of injection of such a daily dose of progesterone followed by oestrogen and the onset and termination of oestrus. The 90- $\mu \mathrm{g}$ dose of $\mathrm{OB}$ is adequate to induce oestrus of about $48 \mathrm{hr}$ duration commencing about $18 \mathrm{hr}$ after injection, while the $30-\mu \mathrm{g}$ dose may be expected to induce oestrus of about $28 \mathrm{hr}$ duration commencing about $22 \mathrm{hr}$ after injection (Scaramuzzi, Lindsay \& Shelton, 1971). Ewes were inseminated $36 \mathrm{hr}$ after the OB injection without reference to teaser rams, i.e. towards the middle of the induced oestrous period.

Two ewes were lost from the experiment by mischance. No attempt was made to replace them because of the necessity to conduct all operations at the predetermined time.

\section{Artificial insemination}

Pooled semen, collected by artificial vagina from three rams and of high quality as assessed visually, was used. For practical purposes, a uniform dose of $0.1 \mathrm{ml}$ containing 450 to $500 \times 10^{6}$ spermatozoa was introduced under the papilla at the cervical os. Care was taken to avoid differences in depth of insemination. Stress was avoided as far as possible and after insemination the ewes were kept in a small pen before slaughter.

\section{Recovery of spermatozoa}

Ewes were killed by an intracardiac injection of sodium pentobarbitone solution (Lethabarb: V.S. Supplies Ltd, Camperdown, New South Wales). The reproductive tract was immediately removed and ligated at the uterocervical junction. The cervix was dissected away from the rest of the tract, using thoroughly cleaned instruments for each animal, and was stored in a plastic bag in a deep-freeze at $-15^{\circ} \mathrm{C}$. Subsequently, each frozen cervix was divided into three equal portions - caudal, mid- and cranial. Recovery and estimation of numbers of spermatozoa in each portion utilized the techniques described by Lightfoot \& Salamon (1970) and Allison \& Robinson (1970). This involved the cutting of the portions of the cervix into longitudinal strips and shaking vigorously with $10 \mathrm{ml}$ saline to dislodge the spermatozoa before counting. This technique is more efficient than flushing. Lightfoot, Croker \& Neil (1967) made counts of spermatozoa after successive flushings of the cervix and in the first flushing recovered only $59 \%$ of the total number of spermatozoa recovered. By contrast, R. J. Lightfoot (unpublished data), on checking the shaking technique using successive washings, recovered in the first washing more than $90 \%$ of the total number of spermatozoa recoverable. A. J. Allison (unpublished results) also checked the technique and in all of ten cervices found the washing from a second shaking to contain less than $2 \%$ of the numbers of spermatozoa present in the first. 
The percentage of inseminated spermatozoa recoverable by this technique from the cervix shortly after insemination is much higher than that recoverable by flushing (Table 1).

Analysis of the data

A split-plot analysis of variance was applied, after adding 2 to each count to avoid zero values, using a $\log _{10}$ transformation. Missing values were inserted, with consequent adjustment of degrees of freedom. Correlation coefficients were calculated for numbers of spermatozoa in successive regions of the tract at each interval of time. The three regions of the cervix were regarded as a linear series for the purpose of analysis.

Table 1. Recovery of spermatozoa from the cervix of ewes by flushing or shaking techniques at various times after insemination

\begin{tabular}{llcc}
\hline \multicolumn{1}{c}{ Reference } & Technique & $\begin{array}{c}\text { Interval from } \\
\text { insemination } \\
(\text { hr })\end{array}$ & $\begin{array}{c}\% \\
\text { Spermatozoa } \\
\text { recovered }\end{array}$ \\
\hline Quinlivan \& Robinson (1969) & Flushing & 1 & 0.5 \\
Mattner, Entwistle \& Martin (1969) & Flushing & 4 & $2 \cdot 3$ \\
Lightfoot \& Restall (1971) & Flushing & $0 \cdot 5$ & $1 \cdot 2$ \\
Allison (1972) & Shaking & 2 & $5 \cdot 5$ \\
\hline
\end{tabular}

* Of numbers inseminated.

Table 2. Estimated corrected mean numbers of spermatozoa recovered from three regions of the cervix in ewes

\begin{tabular}{cccccc}
\hline \multirow{2}{*}{$\begin{array}{c}\text { Time after } \\
\text { insemination } \\
(h r)\end{array}$} & $\begin{array}{c}\text { Dose of } \text { OB } \\
(\mu \mathrm{g})\end{array}$ & \multicolumn{4}{c}{$\begin{array}{c}\text { Estimated mean no. of spermatozoa recovered } \\
\text { from regions of cervix }\end{array}$} \\
\cline { 3 - 6 } & & $\begin{array}{c}\text { Caudal } \\
\left(\times 10^{3}\right)\end{array}$ & $\begin{array}{c}\text { Mid- } \\
\left(\times 10^{3}\right)\end{array}$ & $\begin{array}{c}\text { Cranial } \\
\left(\times 10^{3}\right)\end{array}$ & $\begin{array}{c}\text { Total* } \\
\left(\times 10^{3}\right)\end{array}$ \\
\hline 1 & 30 & 2680 & 51 & 3 & 73 \\
& 90 & 4724 & 552 & 6 & 252 \\
12 & 30 & 135 & 71 & 17 & 54 \\
& 90 & 374 & 1087 & 180 & 418 \\
24 & 30 & 85 & 135 & 31 & 71 \\
& 90 & 177 & 174 & 63 & 125 \\
\hline
\end{tabular}

Means derived from reconversion of $\log _{10}(x+2)$ values. Each value is the mean of five observations.

* These values are not the $\Sigma$ Gaudal, Mid-, and Granial values presented but the reconverted values of the $\Sigma \log$ means used in the analysis.

\section{RESULTS}

Table 2 presents the estimated (reconverted) mean numbers of spermatozoa recovered from each of the three regions of the tract for each treatment combination. Table 3 is an analysis of variance.

There was a highly significant overall decline in the mean numbers of spermatozoa recovered from the caudal to cranial regions of the cervix $(P<0.001)$. This 
relationship altered with the passage of time, the numbers becoming more evenly distributed (time $\times$ region interaction; $P<0.001$ ). At 12 and $24 \mathrm{hr}$, the mid-cervical section contained relatively more spermatozoa than did either of the other regions $(P<0.05)$. At each interval of time and for each region of the tract, fewer spermatozoa were recovered from the ewes treated with $30 \mu \mathrm{g} \mathrm{OB}$ than those treated with $90 \mu \mathrm{g}(P<0.05)$.

Table 3. Split-plot analysis of variance of data for numbers of spermatozoa recovered from three regions of the cervix in ewes after $\log _{10}(x+2)$ transformation

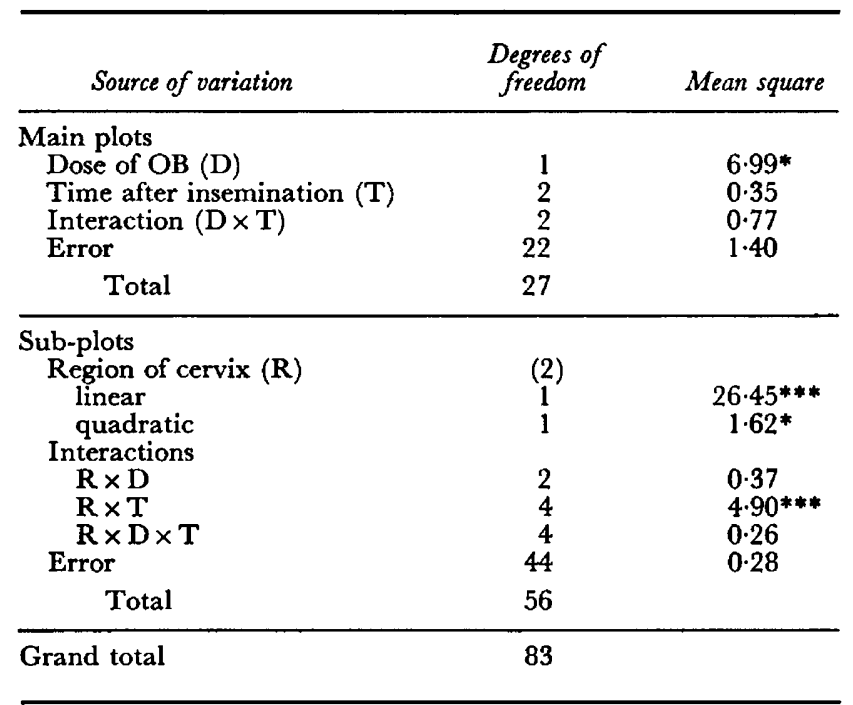

${ }^{*} P<0.05 ;{ }^{* * *} P<0.001$.

Table 4. Table of correlation coefficients for numbers of spermatozoa in three regions of the cervix at three intervals from insemination

\begin{tabular}{|c|c|c|c|c|c|c|}
\hline \multirow{3}{*}{$\begin{array}{c}\text { Region of } \\
\text { cervix }\end{array}$} & \multicolumn{6}{|c|}{ Interval from insemination } \\
\hline & \multicolumn{2}{|c|}{$1 \mathrm{hr}$} & \multicolumn{2}{|c|}{$12 \mathrm{hr}$} & \multicolumn{2}{|c|}{$24 \mathrm{hr}$} \\
\hline & Caudal & Mid & Caudal & Mid & Caudal & Mid \\
\hline $\begin{array}{l}\text { Mid } \\
\text { Cranial }\end{array}$ & $\begin{array}{l}0.57 \dagger \\
0.02\end{array}$ & 0.24 & $\begin{array}{l}0.87^{* * *} \\
0.64^{*}\end{array}$ & $0.83^{* *}$ & $\begin{array}{l}0.91^{* * *} \\
0.73^{* * *}\end{array}$ & $0.83^{* * *}$ \\
\hline
\end{tabular}

All values are positive.

$\dagger P<0.10 ; * P<0.05$; ** $P \leqslant 0.01$; *** $P \leqslant 0.001$.

The nature of dispersal of spermatozoa through the cervix is shown in Table 4. At $1 \mathrm{hr}$ after insemination, the numbers present in the cranial third were not correlated with those in the caudal or mid-thirds. By $12 \mathrm{hr}$, the numbers in successive regions were highly correlated. 


\section{DISGUSSION}

Mattner \& Braden (1969) have shown that only some $50 \%$ of live spermatozoa are recovered by flushing techniques; the rest remain in the crypts. The vigorous shaking used in our technique strips off much of the cervical epithelium with the associated spermatozoa and results in recovery of the majority of the spermatozoa, judging from the relatively high recoveries shown in Table 1 and the low numbers of spermatozoa recoverable in subsequent shakings. Certainly, the proportion recovered is sufficient for use in comparative studies such as that described in this paper.

This study confirms the finding of Allison \& Robinson (1972) that the total number of spermatozoa recovered from the cervix of spayed ewes is affected by the dose of oestrogen involved in the induction of oestrus. It extends it in that it shows the changing pattern of distribution of spermatozoa in the caudal, midand cranial regions of the cervix with the passage of time and the potential effect on this of factors such as change of endocrine status.

The mean numbers of spermatozoa $1 \mathrm{hr}$ after insemination were relatively high in the caudal region of the cervix, of the order of 3 to $5 \times 10^{6}$, and declined markedly towards the cranial third in which the mean was only 3 to $6 \times 10^{3}$. At $12 \mathrm{hr}$, the pattern was significantly altered, with relatively larger numbers in the mid- and cranial regions, particularly in the ewes treated with the higher dose of $\mathrm{OB}$, in which a difference of approximately tenfold between the two treatments attained significance $(P=0.05)$. It could be argued that the higher dose of oestrogen facilitated passage of spermatozoa through the cervix. By $24 \mathrm{hr}$, the distribution of spermatozoa between the three regions of the cervix was more even, with no significant differences between treatments.

The data provide strong evidence against rapid transport through the cervix in that there was no correlation between the numbers of spermatozoa in the caudal and cranial regions $1 \mathrm{hr}$ after insemination. By $12 \mathrm{hr}$, there was a positive correlation and at $24 \mathrm{hr}$, the correlations between the numbers present in the three regions were even higher.

\section{AGKNOWLEDGMENTS}

The authors acknowledge the technical assistance of Mr J. Ellsmore. The project received financial support from the Australian Research Grants Committee. The first author was supported, initially, by a G. D. Searle and Co. Research Studentship and then an Australian Wool Board Post-graduate Scholarship.

\section{REFERENGES}

Allison, A. J. (1972) A comparison of the transport of spermatozoa in spayed and entire ewes. $\mathcal{J}$. Reprod. Fert. 31, 415-423.

Allison, A. J. \& Robinson, T. J. (1970) The effect of dose level of intravaginal progestagen on sperm transport, fertilization and lambing in the cyclic Merino ewe. F. Reprod. Fert. 22, 515-531.

Allison, A. J. \& Robinson, T. J. (1972) The recovery of spermatozoa from the reproductive tract of the spayed ewe treated with progesterone and oestrogen. F. Reprod. Fert. 31, 215-224.

Lightroot, R. J., GrokeR, K. P. \& NeIL, H. G. (1967) Failure of sperm transport in relation to ewe infertility following prolonged grazing on oestrogenic pastures. Aust. F. agric. Res. 18, 755-765. 
Lightroot, R. J. \& Restall, B. J. (1971) Effects of site of insemination, sperm motility and genital tract contractions on transport of spermatozoa in the ewe. 7. Reprod. Fert. 26, 1-13.

Lightroot, R. J. \& Salamon, S. (1970) Fertility of ram spermatozoa frozen by the pellet method. I. Transport and viability of spermatozoa within the genital tract of the ewe. F. Reprod. Fert. 22, 385-398.

Mattner, P. E. \& Braden, A. W. H. (1969) Effect of time on insemination on the distribution of spermatozoa in the genital tract in ewes. Aust. F. biol. Sci. 22, 1283-1286.

Mattner, P. E., Entwistle, K. W. \& Martin, I. G. A. (1969) Passage, survival and fertility of deepfrozen ram semen in the genital tract of the ewe. Aust. F. biol. Sci. 22, 181-187.

Quinlivan, T. D. \& Robinson, T. J. (1969) Numbers of spermatozoa in the genital tract after artificial insemination of progestagen-treated ewes. F. Reprod. Fert. 19, 73-86.

Robinson, T. J. (1959) The estrous cycle of the ewe and doe. In Reproduction in Domestic Animals, Vol. 1, Chap. 9, pp. 291-333. Eds. H. H. Gole and P. T. Gupps. Academic Press, New York.

Scaramuzzi, R. J., Lindsay, D. R. \& Shelton, J. N. (1971) The effect of oestradiol benzoate on the duration of oestrous behaviour in the ovariectomized ewe. F. Endocr. 50, 345-346. 